\title{
Field analysis of indoor air quality in high rise and low rise green offices with radiant slab cooling systems in Malaysia
}

\section{Environment}

Indoor and Built Environment 2015, Vol. 24(2) 174-184 (c) The Author(s) 2013 Reprints and permissions: sagepub.co.uk/

journalsPermissions.nav DOI: $10.1177 / 1420326 \times 13506130$ ibe.sagepub.com (SAGE

\author{
Y. H. Yau' ${ }^{1}$ and S. Hasbi ${ }^{2}$
}

\begin{abstract}
Even though the green building concept is fairly new in Malaysia, the development of this industry has been growing in recent years prior to the launch of Malaysia's own standard, namely the Green Building Index (GBI). One of the criteria assessed in the GBI is the energy efficiency, which takes about $21 \%$ of the overall assessment. Considering this, the passive design has been included in the green building concept to reduce the energy usage without compromising occupant thermal comfort. This study attempts to assess the passive design effectiveness in terms of indoor air quality in green office buildings in the tropics. Two green office buildings that incorporated the radiant slab cooling and conventional cooling system have been selected as case studies. A detailed assessment in terms of thermal comfort parameters (temperature and relative humidity), indoor pollutants' concentration (carbon dioxide, carbon monoxide and formaldehyde) and air movement was carried out. The results showed that the thermal comfort parameters fall within the Malaysian Standard (MS1525:2007) and ASHRAE Standard-55 2010 except for the air movement in both buildings. Based on the results obtained, future buildings using the radiant slab cooling can have a better comfort level from the lesson learned from both buildings.
\end{abstract}

\section{Keywords}

Air conditioning, Green building, Indoor air quality, Malaysia, Radiant slab cooling

Accepted: 30 August 2013

\section{Introduction}

Green building is the recent resort to combat climate change as the technology involved contributes to huge reduction in energy usage and carbon emission. In Malaysia, the demand for green buildings has continued to increase due to environmental conditions, rising energy costs, government support, building code and greater availability of green products. In terms of indoor environment, the green building provides acceptable indoor air quality to the building occupants with minimum energy usage.

Indoor air quality in the office space plays an important role in the occupant's performance and health as the occupants spend almost $10 \mathrm{~h}$ per day in the office in five days per week. Poor indoor air quality due to the air conditioning and ventilation problems and airtight building can lead to sick building syndrome (SBS), ${ }^{1-3}$ which could affect occupants productivity and well being. Several studies ${ }^{4-7}$ show that common work-related signs of the SBS are lethargy, blocked nose, fatigue, dry throat and headache.

The usage of the air conditioner has significantly increased the energy consumption of a building, and thus increase its impacts on the environment in terms of carbon emission. ${ }^{8}$ In addition, the study shows that the occurrence of the SBS is highly associated with the type of ventilation system installed in the building, and often occurs in buildings with the mechanical ventilation

'Department of Mechanical Engineering, University of Malaya, Kuala Lumpur, Malaysia

${ }^{2}$ Department of Mechanical Engineering, National Defense University of Malaysia, Kuala Lumpur, Malaysia

Corresponding author:

Y. H. Yau, Department of Mechanical Engineering, University of Malaya, Kuala Lumpur, Malaysia.

Email: yhyau@um.edu.my 
system compared to the normal ventilation system. ${ }^{9}$ However, the green building design offers a cost-effective solution to solve this problem. Passive designs such as natural ventilation and shading, and cooling techniques such as the radiant cooling or indirect evaporative cooling has been incorporated in the green building design to optimize the occupant thermal comfort, and better indoor air quality and energy savings. ${ }^{10}$ In few separate studies, the radiant slab cooling in conjunction with the conventional cooling system have shown good performance by providing better thermal comfort and air quality indoor environment. ${ }^{11-13}$

Radiant slab cooling has recently created more demand in Europe ${ }^{14}$ as it is viable to create a more comfortable thermal environment with a lower energy usage. ${ }^{13,15-19}$ However, as it is still new and rare in Malaysia, more studies are needed to evaluate the suitability and performance of the radiant slab cooling in the tropic. As the radiant slab cooling is complemented with the conventional air cooling system in hot and humid climates, the main problem of its application is the condensation of the moisture from air limit cooling capacity on the panels, which affects the removing of latent heat load. ${ }^{13,16}$

Many studies have been carried out to assess the indoor air quality in commercial buildings, but only few studies focus on green buildings as it is fairly new and rare in most of the developing countries around the world, including Malaysia. This study is conducted to assess the indoor air quality in the office in the green buildings in the tropics. Two green buildings that employed a cooling system that consists of the radiant slab cooling and conventional system are selected as case studies, namely the high rise (HR) building and low rise (LR) building. These case studies can serve as an assessment in terms of indoor air quality for future green building's design in the tropics.

\section{Methodology}

The indoor air quality study was carried out using the approach established by Cheong and $\mathrm{Lau}^{20}$ to evaluate the indoor air quality for air-conditioned buildings as indicated in Table 1.

\section{Measurement procedures}

Selection of a sampling method used in the indoor air quality study depends on the objectives of the study, the contaminants concern and the required sampling duration. In this case study, the parameters chosen are the room temperature, relative humidity, air velocity and indoor contaminants, which include carbon monoxide $(\mathrm{CO})$, carbon dioxide $\left(\mathrm{CO}_{2}\right)$, formaldehyde $(\mathrm{HCHO})$ and total volatile organic compounds (TVOC). Based on the ASHRAE method, the sampling probe should be located between 0.75 to $1.2 \mathrm{~m}$ from the floor at the middle of the room or an occupied space. If the space is served by different air-handling unit (AHU), one sample should be taken from each floor or space. If the floor space is larger than $3000 \mathrm{~m}^{2}$, the minimum numbers of sampling points suggested are shown in Table 2 below.

Table 2. Numbers of sampling points.

\begin{tabular}{lc}
\hline $\begin{array}{l}\text { Area of } \\
\text { building }\left(\mathrm{m}^{2}\right)\end{array}$ & $\begin{array}{l}\text { Minimum number } \\
\text { of sampling points }\end{array}$ \\
\hline $3000-4999$ & 8 \\
$5000-9999$ & 12 \\
$10,000-14,999$ & 15 \\
$15,000-19,999$ & 18 \\
$20,000-29,999$ & 21 \\
30,000 or more & 25 \\
\hline
\end{tabular}

Table 1. Indoor air quality study methodology.

\begin{tabular}{ll}
\hline Pre-measurement planning stage & - Understand the background of the building \\
& - Review the Mechanical and Electrical drawings \\
Physical measurement stage & - Walk through inspection \\
Evaluation stage & - Field measurement \\
& - humidity indoor contaminants and ventilation study) \\
& - Data analysis \\
Recommendation stage & - Cojective parameters \\
& - Determine implication and causes \\
\hline
\end{tabular}


Field measurement was carried out to measure the indoor air quality parameters such as temperature, relative humidity, contaminants, particle concentration and air velocity. The PPMonitor stand alone system (SAS) and Velocicalc Multi-Function Ventilation Meter were used for the field measurement. The measurement was conducted at several locations in the office space in the building at $1 \mathrm{~m}$ above the floor level. The field measurement was conducted for a week at the HR building and two weeks at the LR building. The results were then compared with the Malaysian MS 1525:2007 standard and ASHRAE Standard 55-2010. At this point, it is pertinent to mention that the real names of the examined green buildings are kept anonymous due to the request from the participating building owners.

\section{Instrumentation}

The indoor air conditions such as the dry bulb temperature (DBT), relative humidity $(\% \mathrm{RH})$, concentration of carbon dioxide $\left(\mathrm{CO}_{2}\right)$, carbon monoxide $(\mathrm{CO})$, total volatile organic compounds (TVOC) and formaldehyde $(\mathrm{HCHO})$ and air velocity (v) are measured using instrumentation as described below.

\section{PPMonitor SAS}

The PPMonitor SAS is used to measure several indoor air quality parameters such as temperature, humidity and air velocity, and indoor contaminants such as carbon dioxide, carbon monoxide, nitrogen dioxide, ozone, sulphur dioxide, total volatile organic compounds and formaldehyde. The results, reports and scheduling options can be assessed immediately, and several results can be displayed in a visual format on the screen as the device has a graphical user interface
(GUI). The sensor ranges are as follows (indicated in Table 3).

\section{VelociCalc Multi-function Ventilation meter}

The VelociCalc Multi-Function Ventilation Meter measures air velocity, airflow, temperature, humidity and pressure. This unit is capable of measuring air velocity from 1.27 to $78.7 \mathrm{~m} / \mathrm{s}$ with $\pm 1.5 \%$ accuracy in its readings.

\section{Q-Trak air quality monitor}

This device measures $\mathrm{CO}_{2}, \mathrm{CO}$, temperature and relative humidity simultaneously. The data collected at 1min log intervals can be saved for 38.9 days. The data logging, analysis and documentation can be done using the TRAKPRO software.

\section{Alnor EBT721 balometer}

The Alnor EBT721 Balometer Electronic Balancing Tool is a detachable multi-purpose digital manometer used to measure the off-grille supply parameter. The unit is capable of measuring the volumetric air flow and temperature by placing the unit under the grille or diffuser.

\section{Building description and theory relevant to radiant slab cooling}

\section{Case study 1: High-rise green building}

The high-rise green building is designed and built based on the sustainable concept, taking into consideration

Table 3. Sensor range of PPMonitor stand alone system (SAS).

\begin{tabular}{ll}
\hline Parameter & Range \\
\hline Temperature (CMOSens Technology) & -40 to $+128^{\circ} \mathrm{C}$ \\
Humidity (CMOSensTechonology) & $0-100 \%$ \\
VOC's (PID) & $0-20 \mathrm{ppm}$ \\
Formaldehyde (electrochemical) & $0-10 \mathrm{ppm}$ \\
Carbon dioxide (NDIR) & $0-5000 \mathrm{ppm}$ \\
Carbon monoxide (electrochemical) & $0-100 \mathrm{ppm}$ \\
Nitrogen dioxide (electrochemical) & $0-20 \mathrm{ppm}$ \\
Sulphur dioxide (electrochemical) & $0-5 \mathrm{ppm}$ \\
Ozone (electrochemical) & $0-1 \mathrm{ppm}$ \\
Particulates & Respirable size, $\mathrm{PM}_{10}, \mathrm{PM}_{2.5}, \mathrm{PM}_{1.0}$ size fractions \\
Air velocity & Measures low velocities down to $0.05 \mathrm{~m} / \mathrm{s}$ \\
\hline
\end{tabular}


the fossil fuel reduction, water savings, green building materials, indoor environmental quality, traffic and transport management, construction and demolition plan and waste minimization. The building energy index (BEI) of this building is projected to be $85 \mathrm{kWh} / \mathrm{m}^{2} /$ year, which is much lower than the standard index of $135 \mathrm{kWh} / \mathrm{m}^{2} /$ year (MS $1525: 2007$ ). The total gross floor area is $14,229 \mathrm{~m}^{2}$ in a total site area of $4928.11 \mathrm{~m}^{2}$. The thin-film solar photovoltaic (PV) panels were installed on the roof, which provide almost $10 \%$ of the building's energy needs and is expected to generate $100,000 \mathrm{kWh}$ per year. The thin film solar PV is $20-40 \%$ more efficient per $\mathrm{kWp}$ compared to the normal PV crystalline due to its high ability to harvest diffuse light and small drop in efficiency when the panels are warmed.

The building is designed in a unique diamond shape to efficiently avoid infiltration due to the advantage of tilted façade. The building's slanted façade, which is self-shading, increases the energy-efficiency of the building. Instead of striking directly to the façade and infiltrate inside the air-conditioned building, the wind striking on the tilted façade would flow below to help ventilate the parking area at the basement level. The perimeter outer walls are tilted at $65^{\circ}$ from horizontal. Due to this, the sun penetration of the west and east façade is strongly reduced while the north and south façades receive no direct sunlight at all. The atrium of the building is exposed to the intense solar radiation during the day to minimize the thermal impact, solar heat gain and for natural lighting purpose. The façade is integrated with internal light shelves to direct natural daylight deep into the office space and help to minimise glare in spaces adjacent to the window. The building has also adopted the radiant cooling with thermal mass cooling storage to reduce its energy consumption for air conditioning as $40 \%$ of the cooling is delivered by the radiant cooling. Water is used to transport the cooling to the room as it is much more efficient compared to using air (conventional air conditioning). The buildings also employed the recycled plaster board, low VOC paint and recycled content carpet to ensure good indoor environmental quality inside the office space.

\section{Case study 2: Low-rise green building}

The low-rise green building serves as a pilot project of a low-energy office in Malaysia. It employed both active and passive designs and generates energy for its own usage. This building does not use fossil fuel energy sources; since its electricity was generated by its own solar-building-integrated-photovoltaic (BIPV) systems. Four different solar BIPV using different technologies are implemented in this building. The electricity produced by the BIPV systems is recorded and is directly consumed. Therefore, there is no battery installed in the system. Currently, the BIPV system produces approximately $103 \mathrm{MWh}$ yearly based on the actual outputs in three months time. The building energy usage is reduced by the implementation of energy-efficient (EE) characteristics in the building. Thus, the total payback time for the system employed is estimated to be less than 22 years according to the technologies used and subsidized electricity tariff.

The building utilizes the passive techniques such as orientation and vegetation, balanced with active techniques such as the energy saving lighting system, double-glazed window, floor slab cooling and thermal wall at its west and east façades in order to achieve the super energy-efficiency outputs. High performance glazing and sealed double glazing have been implemented and proven to be effective in harnessing high visible low infra-red and ultra-violet transmittance and preventing unwanted heat radiation into the building.

The building also incorporates the floor slab cooling complemented by the conventional cooling system as illustrated in Figure 1. The embedded tubes are placed within the concrete floor slabs to the room below and above them. The floor slab cooling produces cooling by releasing the stored cooling effects to the room during operating hours. The indoor air quality is conserved through the dehumidification process. The supply hot and humid fresh air is replaced with cooler and drier exhaust air by using the desiccant heat wheel that reduces the energy usage to dehumidify the indoor air moisture in the building.

\section{Background of radiant/chilled slab cooling system in the building in Malaysia}

Radiant slab cooling has recently created more demand in Europe ${ }^{14}$ as it is viable to create a comfortable thermal environment with a lower energy usage..$^{13,15-19}$ However, as it is still very new and rare in Malaysia, more studies are needed to evaluate the suitability and performance of the radiant slab cooling in the tropics. As the radiant slab cooling is complemented with the conventional air cooling system in hot and humid climates, the main problem of its application is the condensation of the moisture from air limit cooling capacity on the panels, which affects the removal of latent heat load. ${ }^{13,16}$ However, if there is no condensation, the relative humidity in the vicinity of the radiant slab is still much higher than in the occupied zone, which would encourage the proliferation of moulds and other microbes to become a contaminant source in the room.

The radiant slab cooling transfers almost half of the heat through radiation, ${ }^{21}$ and thus the volume of the supplied air can be reduced and lowered the energy used to transport the air. ${ }^{13}$ It increases the heat 


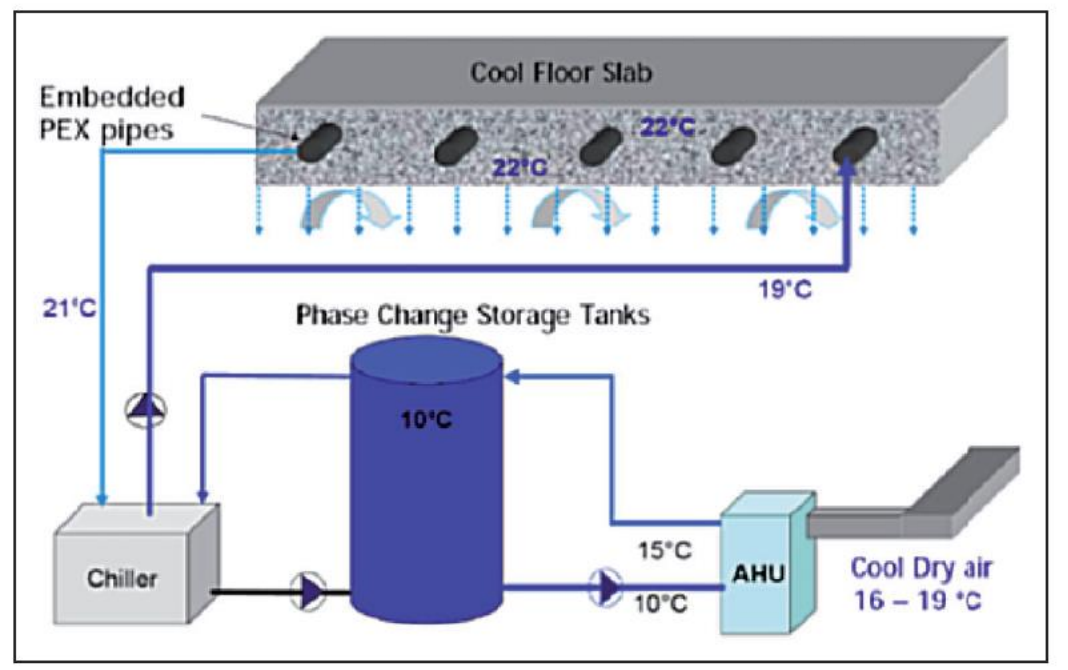

Figure 1. Air-conditioning system installed in LR building.

rejection by radiation and decreases the perspiration compared to the conventional air cooling system. ${ }^{22}$ In terms of energy consumption, $80 \%$ of savings could be achieved given that the occupants are satisfied with the thermal comfort. ${ }^{15,16}$ A climate chamber test has proven that the radiant slab cooling would comply with the ISO 7730:2005 standard. ${ }^{23,24}$

In the examined case studies, the air conditioning in the building is provided by two separate systems, namely the conventional cold air supply system and the radiant slab cooling system. The radiant cooling panel consists of extruded aluminium panels with metal tube linked to one side of the panel. ${ }^{17}$ The concrete slab acts as a thermal storage that cooled during night time. The basis of the slab cooling system design is to cool down the heat masses of the building during night time. Since the highest heat capacity of a building rest in the concrete mass, the direct cooling of the concrete slab with embedded chilled water pipes is the most efficient way to cool the building mass at night that acts as thermal storage for daytime heat load subsequently. This operation would not only bring down the daytime maximum demand, but would also provide the most efficient way to cool the largest portion of heat capacity in the building by direct means, instead of through cooling by the AHU. In the HR building as indicated in Figure 2, the variable air volume (VAV) air system is employed. The VAV system provides cooling to the space by increasing the airflow proportionally based on the cooling load. This approach would alter the air that delivered to the space whilst maintaining the temperature. The VAV system acts as a backup in case where there is a breakdown of the radiant slab cooling.

The AHU operation and slab cooling charging cannot run simultaneously. During operation of the AHU in the daytime, the motorized valves are applied to isolate the slab cooling to shut down the chilled water supply system. The slab cooling can only be charged during night time. The time for full charging of the slab differs from time to time and would depend on the weather conditions. The dew-point of the slab surface in the tropics' condition is $18^{\circ} \mathrm{C}$. The surface of the chilled floor slab temperature is predicted to be approximately $20-23^{\circ} \mathrm{C}$ to prevent condensation occuring on the slabs. A recent study has indicated that the supply cooling water temperature should be limited to $24-25.8^{\circ} \mathrm{C}$ to avoid condensation of the air moisture in the panels. ${ }^{16}$ The slab cooling would take away almost $30 \%$ of the sensible heat, and thus the supply airflow can be relatively low. More often than not, these design features would lower the air movement and increase the relative humidity due to the low dehumidification. The implementation of radiant slab cooling is advantageous as the conventional air conditioner in the building can be downsized to save energy whilst the usage of water and pump would reduce the energy used to transport the cooling around the building. The downsized AHU would prevent condensation on the chilled slab and provide adequate fresh air to the occupants. The system would also improve the acoustic comfort by reducing the air ventilation rate and noise caused by the ducts.

\section{Link to Full-Text Articles :}

http://ibe.sagepub.com/content/24/2/174.full.pdf 